\title{
PINBA: a Construção de um Programa para a Baixada Fluminense
}

\author{
PINBA: the Construction of a Program for Baixada Fluminense \\ Icléa Lages de Melo ${ }^{1}$ \\ 1 Professora assistente. Faculdade de Educação da Baixada Fluminense (FEBF/UERJ), Brasil. E-mail: iclelages@superig.com.br
}

Recebido em: 31/03/2015 | Aprovado em: 14/10/2015

DOI: 10.12957/interag.2016.15904

\section{Resumo}

Trata do relato de uma experiência do Programa Integrado de Pesquisa e Cooperação Técnica na Baixada Fluminense (PINBA). Este desenvolve atividades extensionistas, apoiadas em estudos $e$ pesquisas sobre políticas, educação e cultura tendo como pano de fundo a estrutura sócio-política e cultural da região da Baixada Fluminense, como também a pesquisa e preservação da sua memória e história. Este programa integra diferentes projetos de extensão, pesquisa e estágio interno complementar, focados na Baixada Fluminense, articulando o ensino, a pesquisa e a extensão. A Faculdade de Educação da Baixada Fluminense (FEBF/UERJ) por estar localizada nessa região, vem mantendo permanente diálogo com a sociedade, buscando estimular a criação cultural, promover e divulgar não apenas a Instituição, mas, sobretudo os conhecimentos que nela são produzidos sobre a Baixada. Eventos como o "FEBF na Praça”, "Baixada na FEBF", comemoração do "Dia da Baixada" e visitas guiadas a espaços históricos em parceria com entidades que pesquisam e divulgam a região, representam e configuram um eixo metodológico que é o de articular o local e o global. Para integrar o banco de dados sobre a região foi produzido em 2014 o primeiro volume de um CD (ISSN 23581328). O volume dois já se encontra em processo de elaboração e será concluído após a realização do próximo evento em maio de 2015 com novas produções, indo ao encontro de uma das finalidades da educação superior que é a divulgação de conhecimentos que constituem patrimônio e comunicar o saber do ensino de publicações ou outras formas de comunicação.

Palavras-chave: Baixada Fluminense; história; política educacional; ação extensionista.

Área temática: Educação.

Linha de extensão: Desenvolvimento Regional.

\begin{abstract}
This is the report of an experiment of the Integrated Program of Research and Technical Cooperation in Baixada Fluminense (PINBA). The Program develops community activities supported by studies and research on politics, education and culture, having the socio-cultural and political structure of the region as background, as well as the research and preservation of its memory and history. This program integrates different projects of research, community work and complementary internship, whose focus is on Baixada Fluminense, and which articulate teaching, research and community work. The FEBF/UERJ, located in this region, has been holding permanent dialogue with society, seeking to stimulate cultural creation, to promote and publicize not only the Institution but especially the knowledge that is produced in Baixada Fluminense. Events such as the "FEBF na Praça", "Baixada na FEBF", the celebration of "Baixada Day" and guided tours to historic sites (in partnership with organizations which research and promote the region) represent and constitute a methodology that articulates the local and the global. In order to integrate the database about the region, a CD (ISSN 2358-1328) was produced in 2014. A second volume $C D$ is already being produced and it will be completed after the next event in May 2015, featuring new creations. It meets one of the purposes of higher education: to publicize knowledge that constitutes heritage and to communicate the knowledge of teaching publications or other means of communication.
\end{abstract}

Keywords: Baixada Fluminense; history; educational politcs. 


\section{Introdução}

“[...] patrimônio é algo definido socialmente. Não é qualquer objeto que é visto como pertencentes a nossa cultura, mas aqueles que socialmente ganham valor simbólico”. (Jorge Najjar)

Tudo começou quando identificamos que, embora a Faculdade de Educação da Baixada Fluminense (FEBF/UERJ) esteja há anos ocupando espaço em Duque de Caxias, a unidade ainda era muito desconhecida pela população desse município, em especial da Vila São Luís, bairro onde está situada. E mais: que os nossos acadêmicos, na sua maioria, não conhecem a região em que vivem e estudam e que será um provável espaço de atuação profissional.

Nesse sentido, com o objetivo de fazer com que a FEBF/UERJ se tornasse conhecida, o Programa Integrado de Pesquisa e Cooperação Técnica na Baixada Fluminense (PINBA) buscou pensar, em parceria com outros setores da unidade, eventos que possibilitassem à comunidade esse conhecimento. Assim, junto com a Coordenação do Desenvolvimento Acadêmico (CDA), os Centros Acadêmicos de Pedagogia e Geografia, e o Laboratório de Audiovisual (Laborav), convergirmos para essa caminhada.

\section{Uma Faculdade, um Programa, uma Região}

Inicialmente, faz-se necessário esclarecer que o Programa Integrado de Pesquisa e Cooperação Técnica na Baixada Fluminense (PINBA) foi criado em maio de 1992, pelo então Reitor Hesio Cordeiro, por meio do Ato Executivo de Decisão Administrativa ${ }^{\circ}{ }^{\circ}$ 021. Versa no documento que o funcionamento do programa contará com o apoio e infraestrutura da SR-3 (Sub-reitoria 3) e das demais Unidades em instância da UERJ que se façam necessárias. Para tanto, foi desenvolvido pelo Campus Maracanã até 1995, ficando interrompido até 2000. Em maio desse ano, foi transferido para a Faculdade de Educação da Baixada Fluminense (FEBF), pela então Reitora Nilcéa Freire.

De 2000 a 2009, foi coordenado pelo professor Paulo Mainhard após sua aposentadoria. A partir de 2009, o programa se reestrutura e forma um Colegiado, sob 
a coordenação da professora Icléa Lages de Melo. Atualmente o PINBA desenvolve sete Projetos de Extensão, um Projeto de Pesquisa, três Projetos de Monitoria e um Projeto de Estágio Interno Complementar, envolvendo docentes de áreas e departamentos distintos - Geografia, História, Matemática, Pedagogia e participação do Instituto de Aplicação Fernando Rodrigues da Silva (CAP/UERJ). Para a implementação das suas atividades, organiza-se a partir de três eixos: 1 - Educação, Política e Trabalho, 2 - Ambiente e Cultura e 3 - História da Educação e História Local. Todos os projetos têm a região da Baixada Fluminense como contexto de estudo.

O programa pauta ainda suas atividades em três principais linhas: 1) disponibilizando os recursos técnicos e científicos da UERJ aos municípios da Baixada Fluminense e grupos sociais organizados; 2) realizando estudos e pesquisas sobre a realidade política, social, econômica e educacional da região; e 3) apoiando, no que possível, os movimentos sociais organizados, particularmente na área da formação educacional e cultural.

Há que se registrar a participação do PINBA na elaboração da Carta Cultural da Baixada Fluminense, na criação do Fórum Cultural da Baixada Fluminense, na criação do Prêmio Baixada Cultural (anualmente distribuído a personalidades e instituições da região, com destacadas atuações nas principais áreas da cultura) e na criação do Dia da Baixada Fluminense.

A Carta Cultural da Baixada (disponível em https://pinba.wordpress.com/) foi criada em 2000, coordenada pelo PINBA na gestão do Prof. Paulo Mainhard, e pelo IPAHB (Instituto de Pesquisas e Análises Históricas e de Ciências Sociais da Baixada Fluminense). É considerada "um documento síntese” que

\footnotetext{
reafirmou a convicção dos participantes no potencial dos artistas, pesquisadores, historiadores e promotores culturais locais, ao mesmo tempo que foram destacadas diversas diretrizes para nortear a formulação de uma política cultural para a região entre elas [...] o resgate do patrimônio histórico e cultural dos municípios que compõem a região.
}

$\mathrm{Na}$ intenção de formular uma política cultural para a região, consta ainda na Carta, a criação do Dia da Baixada, a ser comemorado no dia 30 de abril. Essa data deve-se à 
inauguração da estrada de ferro que se tornou um marco histórico, pois foi a primeira a ser construída no Brasil e ligava o porto de Mauá - estação da Guia de Pacobaíba - à região de Fragoso. Esse dia, oficializado pela Lei $\mathrm{n}^{\circ}$ 3.822, de 02/05/2002, é comemorado desde 2001 e tem por finalidade celebrar os valores históricos, sociais e humanos da região, colaborando para o fortalecimento da autoestima da população. Entende-se que a Baixada Fluminense é composta por 13 municípios: Belford Roxo, Duque de Caxias, Guapimirim, Itaguaí, Japeri, Magé, Mesquita, Nilópolis, Nova Iguaçu, Paracambi, Queimados, São João de Meriti, Seropédica. "No entanto, muitas outras obras e pesquisadores em seus recortes, consideram a região com uma composição de quatorze municípios.” ${ }^{2}$, incluindo Mangaratiba.

Essa região tem uma população de aproximadamente 4 milhões e 500 mil habitantes, exercendo um papel importante nos aspectos político, econômico e social, por contemplar $1 / 3$ da população do Estado. Torres ${ }^{3}$ contribui para o entendimento do ser "baixada" ao dizer que:

\footnotetext{
A topografia da Baixada Fluminense, na área do entorno da Baia da Guanabara, apresenta-se bastante diversificada, na realidade chamamos de baixada devido ao predomínio de terrenos com cotas bastante baixas em relação ao mar, no entanto longe de ser área abaixo do nível do mar" [...] os municípios de Duque de Caxias e Magé, em toda a extensão, o predomínio é de baixadas com algumas elevações perdidas ao longo do território que costeia a baia da Guanabara.
}

\section{FEBF na Praça \& Baixada na FEBF}

A Lei de Diretrizes e Bases da Educação Nacional (LDBEN 93/96), no inciso IV do capítulo que trata da Educação Superior, vigora que a mesma tem por finalidade "promover a divulgação de conhecimentos culturais, [...] que constituem patrimônio da humanidade e comunicar o saber através do ensino, de publicações ou outras formas de comunicação". Nesse sentido, a Carta Cultural, dentre outras, propõe "que as Universidades e Faculdades da Baixada motivem seus alunos dos cursos de graduação e pós-graduação e nas diferentes áreas de conhecimento, a pesquisarem sobre a realidade da Baixada" ${ }^{\text {. }}$

O princípio do desenvolvimento do espírito científico e do pensamento reflexivo faz parte do compromisso que a FEBF/UERJ busca junto aos nossos acadêmicos, 
sobretudo por ser a primeira faculdade pública de formação de educadores, na Baixada. Esse pensamento nos permite compreender

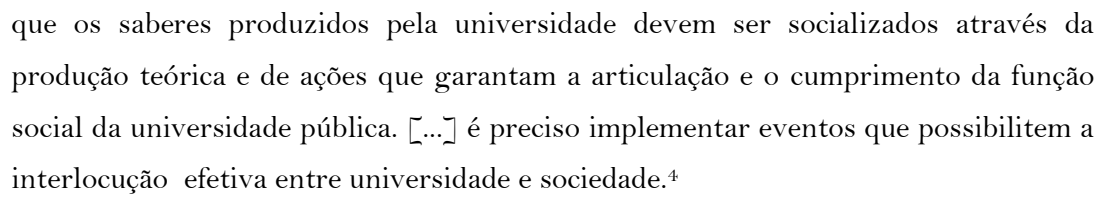

Na busca por nossos objetivos, fizemos várias reuniões com os parceiros já citados e após discussões e sugestões, entendemos que deveríamos realizar ações e /ou eventos com o objetivo de tornar mais visível para a comunidade do entorno, como também para a população do município, a presença da UERJ. Assim, optamos em realizar três eventos: "FEBF/UERJ na Praça", "Baixada na FEBF" e "Visita a Espaços Históricos da Baixada Fluminense", realizados nos dias 17 e 19 de agosto e $1^{\circ}$ de setembro de 2011 , respectivamente.

O primeiro - "FEBF/UERJ na Praça" - 17 de agosto foi literalmente na praça: na "Praça da Bandeira", chamada pelos moradores de Praça da Vila São Luis, próxima à nossa unidade (FEBF). Buscamos cantores da Baixada, diálogo com a paróquia local, apoio da Secretaria Municipal de Cultura, apoio dos nossos parceiros externos, apoio da Polícia Militar e outros. 


\section{CONHEÇA A FEBF/UERJ}

Você sabia.

4.) Que existe uma Faculdade da UERJ na Vila São

Luís desde 1998?

(15) Que é pública, gratuita e de boa qualidade?

(1) Que possui 03 cursos de graduação: Licenciatura em Pedagogia, Licenciatura em Matemática e Licenciatura em Geografia, e dois cursos de pós-graduação: uma especialização e um mestrado?

(1) Que os alunos da FEBF possuem altos índices de aprovação em concursos públicos?

(1) Que A FEBF desenvolve vários projetos, cursos, oficinas, palestras $e$, além disso, possui uma biblioteca aberta à comunidade?

Se você não sabia...

Venha conhecer a FEBF!

\section{www.febf.uerj.br}

Rua General Manoel Rabelo $s / n$, Vila São Luís (Brizolão)

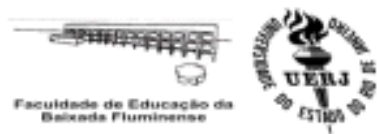

Figura 1. Panfleto FEBF/UERJ na Praça.

O evento teve como objetivo divulgar a Faculdade para a comunidade do entorno, com atividades como: exibição de vídeo, apresentando os diferentes setores da faculdade; fixação, em árvores e tripés, de banners dos diversos projetos lá desenvolvidos; fotografias que retratam a Baixada Fluminense, exibidas em telões; e também cantores da região. Foram distribuídos para a comunidade panfletos (Figura 1) que apresentavam, de forma sucinta, a FEBF, informando sobre a existência dessa unidade naquele bairro. Nesse momento, os nossos estudantes conversavam com as pessoas que por ali transitavam. As atividades foram desenvolvidas das 17 às 21 horas. Dialogando com a paróquia, fizemos um intervalo sem som, no horário da missa, às 19 horas. Na 
celebração da missa, o padre abriu um espaço para que falássemos sobre o evento com os fiéis que lá estavam.

O "Baixada na FEBF" - 19 de agosto teve como objetivo identificar e refletir sobre a produção de estudantes e egressos dos cursos de graduação e da pós-graduação da FEBF, sobre a Baixada Fluminense. Foram abertas inscrições para apresentação de trabalhos do público- alvo, que foram alunos e ex-alunos dos diferentes cursos oferecidos pela instituição (Pedagogia, Matemática, Geografia e Pós- graduação).

Os trabalhos foram encaminhados ao Comitê de Avaliação para apreciação, uma vez que critérios foram estabelecidos para tal produção. Os professores da instituição que formaram esse grupo foram: Adriana Gomes, Alzira Batalha, Elaine Queiroz, Gilcilene Barão, Marilda Flores e Wânia Gonzalez.

No desenvolvimento dessa programação, foi realizada palestra de abertura com o tema “A FEBF na Baixada e a Baixada na FEBF”, proferida pelo prof. Paulo Christiano Mainhard. Ainda nesse evento, foram formadas mesas com apresentação das produções selecionadas.

Os trabalhos foram apresentados na parte da manhã e à noite. A mesa da manhã foi coordenada pela prof ${ }^{a}$ Isabel Pinto, no auditório. As mesas da noite, simultaneamente em duas salas, coordenadas pelos professores Lincoln de Araújo Santos e Vera Lucia Leite Campos. Considerando a relevância de promover e divulgar as pesquisas e produções sobre a região, apresentamos, na Tabela 1 abaixo, os títulos e autores dos textos inscritos:

\begin{tabular}{l|l}
\multicolumn{1}{c|}{ TíTULO } & \multicolumn{1}{c}{ AUTOR } \\
\hline $\begin{array}{l}\text { A história da Baixada Fluminense o Mosteiro } \\
\text { de São Bento }\end{array}$ & $\begin{array}{l}\text { Elias Ramos, Elisa Tavares Ribeiro, } \\
\text { Marcelle Marcolino e Marcos } \\
\text { Antonio Juvino }\end{array}$ \\
\hline $\begin{array}{l}\text { A importância da história local para o ensino de } \\
\text { história: um olhar para o município de Duque de } \\
\text { Caxias }\end{array}$ & Aldiceia Pereira \\
\hline
\end{tabular}




\begin{tabular}{|c|c|}
\hline Alfabetização por meio da música & $\begin{array}{l}\text { Danúbia Baltazar da Cruz e Maria } \\
\text { de Fátima Paiva Almeida }\end{array}$ \\
\hline $\begin{array}{l}\text { Desafios e perspectivas dos manguezais no } \\
\text { município de Magé - Baixada Fluminense }\end{array}$ & $\begin{array}{l}\text { Gabriel de Lima Souza e Jessica } \\
\text { Damiana Fernandes }\end{array}$ \\
\hline $\begin{array}{l}\text { Educação ambiental, currículo e cidadania o } \\
\text { caso do município de Duque de Caxias }\end{array}$ & $\begin{array}{l}\text { Cleonice Puggian, Milena da S. M. } \\
\text { Ribeiro Nogueira e Gabriel de Lima } \\
\text { Souza }\end{array}$ \\
\hline $\begin{array}{l}\text { Entre o samba e o funk, uma experiência com o } \\
\text { ballet clássico caminhos e possibilidades na } \\
\text { comunidade da Prainha }\end{array}$ & Hugo Moreira Lima \\
\hline $\begin{array}{l}\text { Feira da Vila São Luiz um lugar intermitente e } \\
\text { de culturas }\end{array}$ & $\begin{array}{l}\text { Gilliard Damasio Soares, Jonatan de } \\
\text { Jesus Gomes e Robson Marcello da } \\
\text { Silva }\end{array}$ \\
\hline $\begin{array}{l}\text { História e memória da Faculdade de Educação } \\
\text { da Baixada Fluminense }(\mathrm{FEBF}) \text { - de sua origem } \\
\text { à conquista da autonomia como unidade } \\
\text { universitária da UERJ }\end{array}$ & Lilian de Oliveira Machado \\
\hline O estágio como espaço de formação profissional & Andréa Gomes da Silva \\
\hline $\begin{array}{l}\text { Processos de segregação urbana e conflitos } \\
\text { socioambientais na Baixada Fluminense: o caso } \\
\text { da Cidade dos Meninos }\end{array}$ & $\begin{array}{l}\text { Lucia A. S. de Souza, Thaís Rosa e } \\
\text { Fernanda Martins }\end{array}$ \\
\hline $\begin{array}{l}\text { Rodas de leitura na biblioteca do CAC relato de } \\
\text { experiência }\end{array}$ & Ariana de Assis da Silva \\
\hline
\end{tabular}

Tabela 1. Pesquisas e Produções sobre a Baixada Fluminense.

Observa-se que a temática retrata a realidade da região, indo ao encontro da matriz teórica e metodológica do programa, que visa ações que contemplem e busquem um verdadeiro programa para a Baixada, como também integrar o banco de dados sobre a região. Pressupõe ainda pesquisar o local articulado com o global, considerando, inclusive, a grande tradição histórica de possuir rico patrimônio cultural e formação a 
partir de vários grupos étnicos. Assim, as produções passam pelo Mosteiro São Bento; pela história local - Duque de Caxias; pelo manguezal de Magé; pelo currículo e cidadania; ballet clássico e funk na comunidade da Prainha em Duque de Caxias; feira da Vila São Luiz; memória da FEBF; rodas de leitura em São João de Meriti; conflitos sócio ambientais na região e outros.

A "Visita a Espaços Históricos da Baixada Fluminense" - $1^{\circ}$ de setembro teve o roteiro elaborado pelo Centro de Referência Patrimonial e Histórico da Baixada Fluminense (CRPH), parceiro do PINBA, e contemplou os municípios de Duque de Caxias e Magé. Foi guiada pelo Prof $^{\circ}$ Nielson Rosa Bezerra e teve como objetivo possibilitar a ampliação do conhecimento sobre locais históricos dessa região por parte dos estudantes dos cursos de graduação e pós-graduação da FEBF.

Dentre esses locais, destacamos: 1) A Fazenda São Bento (1591), situada em Duque de Caxias onde se encontra o casarão dos monges beneditinos; 2) Igreja Santa Terezinha (1647), marco da formação dos municípios de São João de Meriti e Duque de Caxias; 3) Igreja Nossa senhora do Pilar (1612), tombada como patrimônio histórico brasileiro; 4) Igreja de Nossa Senhora da Guia de Pacobaíba, em Magé, fundada em 1640, tombada pelo IPHAN; 5) Marco da Estrada Real, em Magé, um dos caminhos determinados pela Coroa Portuguesa para que o ouro deixasse as terras mineiras.

\section{Ponto de chegada}

Esses trabalhos culminaram no CD: V.1 - FEBF/UERJ na Praça \& Baixada na FEBF novembro/2014. ISSN 2358-1328 (disponível em https://pinba.wordpress.com/). A produção do CD levou três anos para ser concretizada, pelas inúmeras dificuldades estruturais, técnicas e humanas. Com o apoio do Laboratório de recursos audiovisuais (LABORAV) e do Laboratório de Informática, mesmo com as dificuldades anunciadas, o CD foi finalmente lançado em 2014, no Evento "I SEGRAF" Semana da Graduação da FEBF. Na ocasião, participaram do evento representantes da SR1, SR2 e SR3. Este último foi representado pela prof ${ }^{a}$ Nadia Pimenta Lima, coordenadora do DEPEXT ${ }^{5}$, que nos estimulou a escrever esse artigo, destacando a importância do registro/divulgação de eventos promovidos pelos programas e projetos. 
Mais uma vez buscamos a legislação, ao considerar como uma das finalidades da educação superior "promover a extensão, aberta à participação da população, visando à difusão das conquistas e benefícios resultantes da criação cultural e da pesquisa científica e tecnológica geradas na instituição” (LDBEN 9394/96, art. 43, inciso VII) ${ }^{6}$.

Portanto, para a continuidade dessa produção e difusão de conquistas, novos conhecimentos e metodologias, o PINBA anuncia a publicação do segundo volume do CD, que será produto de trabalhos a serem apresentados no Evento "Dia da Baixada", a ser realizado nos dias 14 e 15 de maio de 2015 , quando estaremos celebrando o dia 30 de abril. Desde o mês de fevereiro, foram abertas inscrições para trabalhos sobre a Baixada. O evento anterior foi restrito aos alunos e ex- alunos. Tendo em vista a relevância e a dimensão que alcançou, estamos agora abrindo para a comunidade externa. O público- alvo são alunos, professores e pesquisadores. A temática do evento é "Políticas Públicas na Baixada: educação, trabalho e território" com uma programação que está sendo divulgada amplamente na região e que pode ser visualizada no site/blog do PINBA e por meio de divulgação nas redes sociais na internet.

\section{Considerações finais}

A FEBF, como instituição pública do Ensino Superior na Baixada, tem um valor simbólico inestimável como lugar de memória. "Deve-se tê-la não só como patrimônio cultural, mas também educacional, social e político, com relevância tanto para a região em que se situa quanto para as pessoas que nela transitam”7.

Por ter uma história de lutas que se inicia nos anos 60, com a criação do curso de Pedagogia, passando pela incorporação à UERJ, pela transformação em unidade universitária ao prédio na Vila São Luis é que a vemos como patrimônio cultural, mas também educacional, social e político. Hoje, oferece licenciatura em Pedagogia, Geografia e Matemática; cursos de pós-graduação lato sensu: especialização em Organização Curricular e Prática Docente na Educação Básica, Gestão dos processos educativos na escola. No nível strictu sensu, oferece o Mestrado em Educação, Cultura e Comunicação em Periferias Urbanas. 
Identificamos nessa caminhada de lutas, conquistas, eventos, divulgações e produções, o impacto na formação dos acadêmicos, tanto no aspecto técnico, quanto pessoal, político e social. Isto se configura nas seguintes falas dos bolsistas do programa: "permite vivenciar uma estrutura universitária, transgredindo os muros da universidade através dos diferentes projetos de extensão e pesquisa, não ficando somente no teórico, no texto, no quadro, na sala de aula, na prova, o que nos possibilita adquirir novos saberes" e ainda "o projeto me fez desmistificar a visão estereotipada que tinha sobre a Baixada, embora tenha nascido, criada e atualmente ainda moradora dessa região” .

E assim, nossos desafios continuam, buscando diminuir cada vez mais o distanciamento entre a Universidade e a realidade da Baixada Fluminense, através das suas atividades, vislumbrando a conquista de igualdade social e assim evidenciando a FEBF como espaço que consolida o sentido de uma universidade pública na Baixada.

\section{Referências}

1. TORRES, Genesis. Em busca da Memória. Crônicas, Registros e Poesia. RJ: WAK, 2003.

2. BRAZ, Antonio Augusto \& ALMEIDA, Tania Maria A. de. De Meriti a Duque de Caxias: encontro com a história da cidade. Caxias: APPH - Clio, 2010.

3. TORRES, Genesis. O ambiente natural e os limites. IN: TORRES, Gênesis. (org) Baixada Fluminense. A construção de uma história. RJ: INEPAC, 2008.

4. BARÃO, Gilcilene. MELO, Icléa Lages de. FEBF: Ações, desafios extensionistas e suas articulações com a pesquisa e o ensino. Revista ADVIR, nº 26, junho de 2011.

5. DEPEXT. Relatório do Programa Integrado de Pesquisa e Cooperação Técnica na Baixada Fluminense (PINBA) FEBF/UERJ, 2014.

6. BRASIL. Lei no 9394, de 20 de dezembro de 1996. Estabelece as Diretrizes e Bases da Educação Nacional (LDBEN).

7. MELO, Icléa Lages de \& LIMA, Hugo Moreira. Faculdade de Educação da Baixada Fluminense (FEBF/UERJ): uma história, várias lutas. Revista Pilares da História ano $12-\mathrm{n}^{\mathrm{o}} 13$ - maio de 2013. 